\title{
The HIA instrument on board the Tan Ce 1 Double Star near-equatorial spacecraft and its first results
}

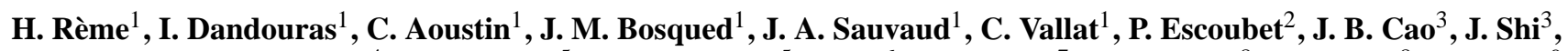 \\ M. B. Bavassano-Cattaneo ${ }^{4}$, G. K. Parks ${ }^{5}$, C. W. Carlson ${ }^{5}$, Z. Pu ${ }^{6}$, B. Klecker ${ }^{7}$, E. Moebius ${ }^{8}$, L. Kistler ${ }^{8}$, A. Korth ${ }^{9}$, \\ R. Lundin ${ }^{10}$, and the HIA team \\ ${ }^{1}$ Centre d'Etude Spatiale des Rayonnements (CESR), Toulouse, France \\ ${ }^{2}$ European Space Research and Technology Center (ESTEC), ESA, The Netherland \\ ${ }^{3}$ Center for Space Science and Applied Research (CSSAR), Beijing, China \\ ${ }^{4}$ Istituto di Fisica dello Spazio Interplanetario (IFSI), Roma, Italy \\ ${ }^{5}$ Space Sciences Laboratory (SSL), Berkeley, USA \\ ${ }^{6}$ Peking University, Beijing, China \\ ${ }^{7}$ Max-Planck-Institut fr extraterrestrische Physik (MPE), Garching, Germany \\ ${ }^{8}$ University of New Hampshire (UNH), Durham, USA \\ ${ }^{9}$ Max Planck Institute for Solar System Research (MPS), Lindau, Germany \\ ${ }^{10}$ Swedish Institute of Space Physics (IRF), Kiruna, Sweden
}

Received: 22 February 2005 - Revised: 15 May 2005 - Accepted: 23 May 2005 - Published: 8 November 2005

Part of Special Issue "Double Star - First Results"

\begin{abstract}
On 29 December 2003, the Chinese spacecraft Tan Ce 1 (TC-1), the first component of the Double Star mission, was successfully launched within a low-latitude eccentric orbit. In the framework of the scientific cooperation between the Academy of Sciences of China and ESA, several European instruments, identical to those developed for the Cluster spacecraft, were installed on board this spacecraft.

The HIA (Hot Ion Analyzer) instrument on board the TC-1 spacecraft is an ion spectrometer nearly identical to the HIA sensor of the CIS instrument on board the 4 Cluster spacecraft. This instrument has been specially adapted for TC-1. It measures the 3-D distribution functions of the ions between $5 \mathrm{eV} / \mathrm{q}$ and $32 \mathrm{keV} / \mathrm{q}$ without mass discrimination.

TC-1 is like a fifth Cluster spacecraft to study the interaction of the solar wind with the magnetosphere and to study geomagnetic storms and magnetospheric substorms in the near equatorial plane.

HIA was commissioned in February 2004. Due to the $2 R_{E}$ higher apogee than expected, some in-flight improvements were needed in order to use HIA in the solar wind in the initial phase of the mission. Since this period HIA has obtained very good measurements in the solar wind, the magnetosheath, the dayside and nightside plasma sheet, the ring current and the radiation belts. We present here the first results in the different regions of the magnetosphere and in the solar wind. Some of them are very new and include, for example, ion dispersion structures in the bow shock and ion
\end{abstract}

Correspondence to: H. Rème

(henri.reme@cesr.fr) beams close to the magnetopause. The huge interest in the orbit of TC-1 is strongly demonstrated.

Keywords. Magnetospheric Physics (Magnetopause, cusp, and boundary layers, Magnetosheath, Solar windmagnetosphere interactions)

\section{Introduction}

The Double Star program, prepared in cooperation between China and ESA, has given an opportunity to add new measurement points with identical instruments to the four Cluster spacecraft. The spare model of the Cluster HIA instrument (Rème et al., 2001), after modifications and adaptations, has been put on board the near-equatorial TC-1 spacecraft launched on 29 December 2003. The TC-1 orbit is $570 \mathrm{~km} \times 79000 \mathrm{~km}\left(\sim 13.4 R_{E}\right)$, with a $28^{\circ}$ inclination orbit.

This paper is a full description of the TC-1 HIA instrument and includes some first results in the different regions covered by the spacecraft in and near the magnetosphere.

\section{Description of the HIA instrument on board the TC-1 spacecraft}

\subsection{The HIA instrument hardware}

The HIA (Hot Ion Analyser) experiment on board the Double Star TC-1 spacecraft is based on the HIA instrument, 


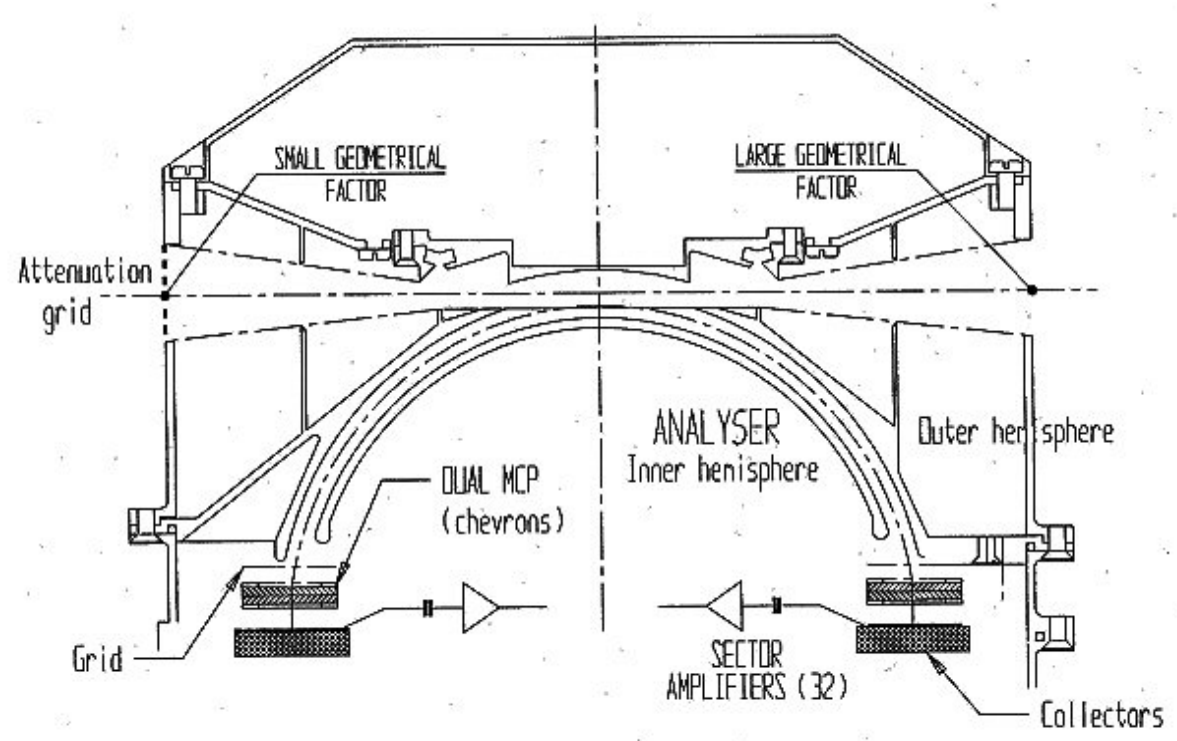

Fig. 1. HIA electrostatic analyser.

which is one of the two different sensors that constitute the CIS (Cluster Ion Spectrometry) experiment on board the four Cluster spacecraft (Rème et al., 2001). However, HIA on Double Star was adapted to the TC-1 spacecraft and orbit, and has some differences with respect to the Cluster HIA.

HIA is an ion energy-spectrometry experiment, capable of obtaining full 3-D ion distributions with good angular and time resolution (one spacecraft spin). HIA combines the selection of incoming ions, according to the ion energy per charge by electrostatic deflection in a quadrispherical analyser, using 2 hemispheric plates, with a fast imaging particle detection system. This particle imaging is based on microchannel plate (MCP) electron multipliers and position encoding discrete anodes. The energy selection of the ions is done by a fast $0-5000 \mathrm{~V}$ sweeping high voltage. The experiment also comprises a sophisticated single-processor-based instrument control and data processing unit (DPU) and memories, which permits extensive onboard data-processing.

Basically, the analyser design is a symmetrical quadrispherical electrostatic analyser, which has a uniform angleenergy response. The instrument has a uniform $360^{\circ} \times 5.6^{\circ}$ disc-shaped field-of-view and narrow angular resolution capability.

In order to cover populations ranging from magnetosheath/magnetopause ions to tail lobe ions, a dynamic range of more than $10^{5}$ is required. Therefore, HIA consists of two $180^{\circ}$ field-of-view sections, with two different sensitivities (with a $\sim 20$ ratio), corresponding, respectively, to the "high G" and "low g" sections. The "low g" section allows detection of the solar wind, and the required high angular resolution is achieved through the use of 8 sectors on the anode sensor (see Fig. 2), 5.625 $5^{\circ}$ each; the remaining 8 sectors have $11.25^{\circ}$ resolution. The $180^{\circ}$ "high G" section is divided into 16 sectors, $11.25^{\circ}$ each (Fig. 2). For each sensitivity section a full $4 \pi$ steradian scan, consisting of 32 energy sweeps, is completed every spin of the spacecraft, i.e. every $4 \mathrm{~s}$, giving a full 3-D distribution of ions in the energy range $\sim 5 \mathrm{eV} / \mathrm{e}-32 \mathrm{keV} / \mathrm{e}$. The geometry factor is $\sim 7.0 \times 10^{-3} \mathrm{~cm}^{2} \cdot \mathrm{sr} \cdot \mathrm{keV} \cdot \mathrm{keV}^{-1}$ for the "high G" half (over $180^{\circ}$ ), and $\sim 3.7 \times 10^{-4} \mathrm{~cm}^{2} \cdot \mathrm{sr} \cdot \mathrm{keV} \cdot \mathrm{keV}^{-1}$ for the "low g" half. Two blank sectors on the "low g" side avoid cross-talk between the two sensitivities.

Note that the "low g" section, designed mainly for solar wind studies, is a feature from Cluster. For Double Star the instrument operation is mainly on the "high G" section, since the spacecraft orbit rarely crosses the average (modelpredicted) position of the bow shock. However, thanks to the higher apogee than scheduled of the TC-1 spacecraft, and to the bow shock in/out motion around its average position, the spacecraft is frequently found in the solar wind but stays near the bow shock.

The HIA sensor on the TC- 1 spacecraft is a spare model of the Cluster spacecraft but with some new properties:

- The interface board has been changed;

- In order to include radiation shielding, taking into account the orbit of TC-1, the size of the box has been increased by $4 \mathrm{~mm}$ on each side, on the top and on the rear, and the total mass of the sensor is $3.5 \mathrm{~kg}$;

- New interface for telemetry;

- Some changes in Telemetry products;

- New interface for commanding;

- New telemetry data rate: $4.44 \mathrm{kbits} / \mathrm{s}$.

From a mechanical point of view, and taking into account the radiation constraints, the thickness of the box has been 


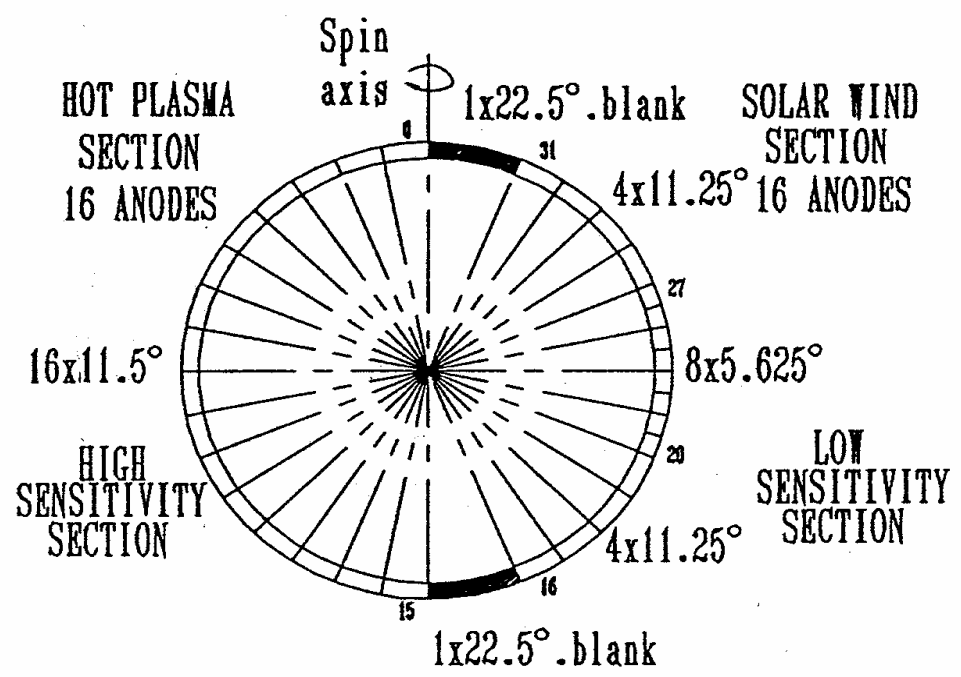

Fig. 2. HIA anode sectoring.

increased : $5 \mathrm{~mm}$ instead of $0.8 \mathrm{~mm}$. The upper plate was redesigned to incorporate the two connectors J01 and J04 (25 pins each). The rear part and one of the sides have the same shape but are thicker. One 4-mm thick shield was added on the other side over the existing plate to leave the connector fixations unchanged.

\subsection{HIA telemetry modes}

HIA has a large amount of flexibility either in the selection of the operational mode or in the reduction of the data necessary to fit the available telemetry bandwith. HIA can thus operate in 16 operational modes (Table 1). These modes, which correspond to different energy sweeping schemes and to different combinations of telemetry products transmitted, can be grouped into 2 main categories:

- Magnetospheric Modes: these modes are relatively simple, i.e. the full energy-angle range is systematically covered. The different telemetry products (including moments) are deduced from the $62 \mathrm{E} \times 88 \Omega$ energy-solid angle count-rate matrices accumulated on the "high G" section.

- Solar Wind Modes (and solar-wind modes with the priority on the upstreaming ions): these modes allow a precise and fast measurement $(4 \mathrm{~s})$ of the ion flow parameters $\left(\mathrm{H}^{+}, \mathrm{He}^{++}\right)$. For that, in the solar wind, the energy sweep range is automatically reduced when the field-of-view of the "low g" section is facing the $45^{\circ}$ sector centred in the solar wind direction. This energy sweep range is adapted every spin, centred on the main solar wind velocity by using a criterion based on the $\mathrm{H}^{+}$ thermal and bulk velocities computed during the previous spin. Moreover, detailed 3-D distributions (e.g. for upstreaming ions and/or for interplanetary disturbances) are included in the basic products transmitted
Table 1. HIA operational modes.

\begin{tabular}{|c|c|}
\hline$=0$ & solar wind mode \\
\hline$=1$ & solar wind/upstreaming ions mode \\
\hline$=2$ & solar wind mode \\
\hline$=3$ & solar wind/upstreaming ions mode \\
\hline$=4$ & solar wind - data compression mode \\
\hline$=5$ & solar wind/upstreaming ions - data compression mode \\
\hline$=6$ & magnetosphere - mode 2 \\
\hline$=7$ & PROM operation \\
\hline$=8$ & magnetosphere - mode 1 \\
\hline$=9$ & magnetosphere - mode 2 \\
\hline$=10$ & magnetosphere - mode 3 \\
\hline$=11$ & magnetosheath/magnetotail - mode 1 \\
\hline$=12$ & magnetosheath/magnetotail - mode 2 \\
\hline$=13$ & magnetosphere - data compression - mode 1 \\
\hline$=14$ & magnetosheath/magnetotail - data compression - mode 2 \\
\hline$=15$ & calibration/test mode \\
\hline
\end{tabular}

to the telemetry. Outside this $45^{\circ}$ sector, the full energy sweep range is used. However, when the field-of-view of the "high G" section is facing the $45^{\circ}$ sector centred in the solar wind direction, the energy sweep stops (and "freezes") above the solar wind alpha particles energy, to avoid a quick degradation of the MCPs by the intense solar wind beam (modes 0-5).

HIA has various options for the selection of different onboard accumulation schemes regarding time, angle, energy, mass distributions in different ways into the memory. These options have no effect on the hardware configuration, on the sweeping scheme and on the telemetry rate.

In contrast to Cluster, on TC-1 there is no burst telemetry mode. Products and telemetry modes are presented in Tables 2-6. 


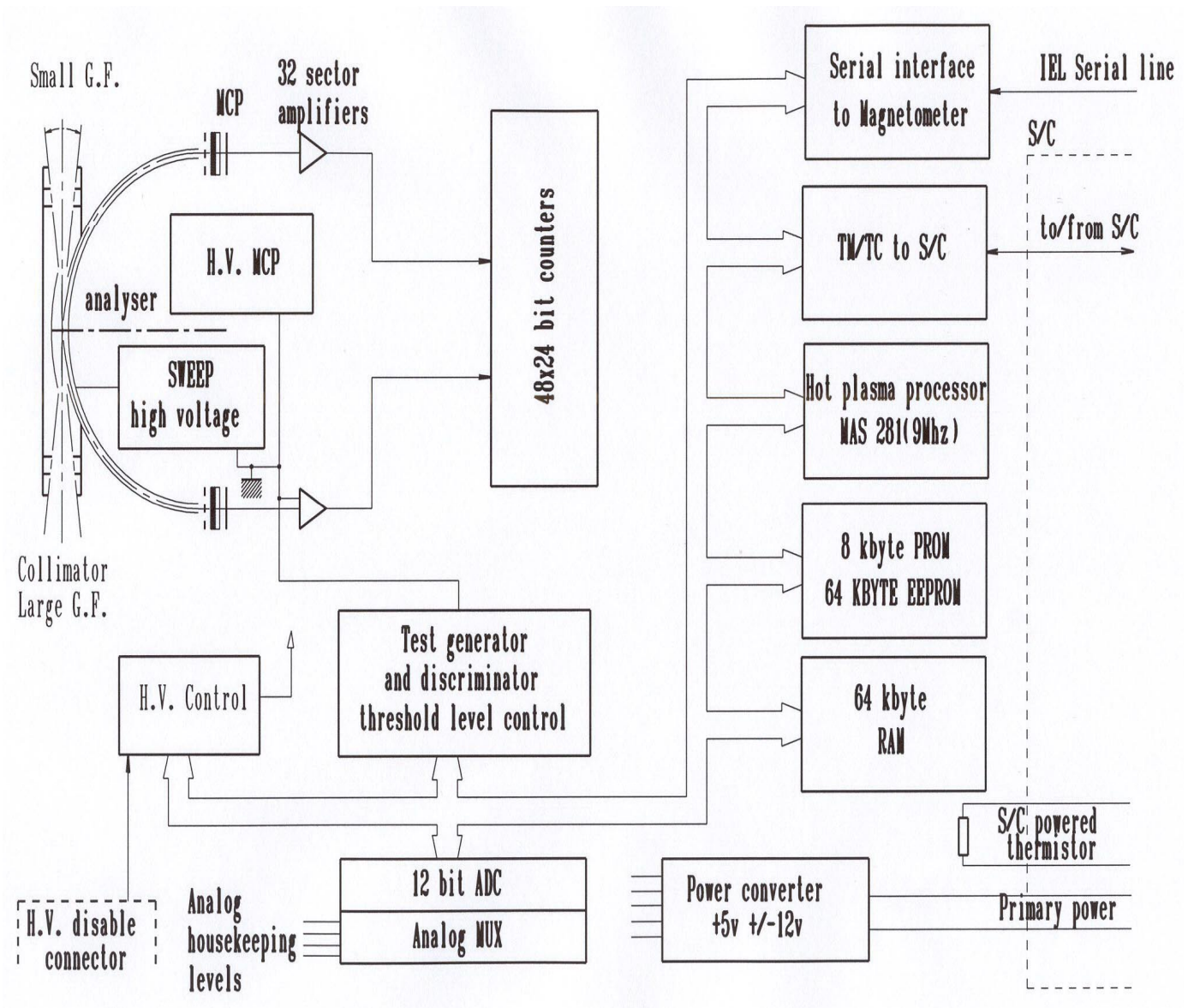

Fig. 3. HIA block diagram.

Table 2. HIA scientific products in magnetospheric modes.

\begin{tabular}{|c|c|c|}
\hline Number & Type & B its/s \\
\hline $\mathbf{P 2}$ & Moments & 118 \\
\hline P6 & $3 \mathrm{D} 31 \mathrm{E} 88 \Omega$ & 5496 \\
\hline P9 & 1D 31E & 251 \\
\hline P12 & PAD 31E 16@ (1spin) & 2004 \\
\hline P17 & $3 D 62 E 88 \Omega$ & 10996 \\
\hline P19 & PAD 31E 16@ (2spins) & 2004 \\
\hline
\end{tabular}

\subsection{HIA measured parameters}

The HIA telemetry comprises onboard calculated moments of the distribution functions, transmitted every spin of the spacecraft (4s), and detailed 3-D distribution functions, transmitted with a time resolution that is mode dependent.

The basic measurements are:

- Moments of the distribution function of the ions: density, ion bulk velocity vector, pressure tensor, heat flux;
Table 3. HIA scientific products in solar wind modes.

\begin{tabular}{|c|c|c|}
\hline Number & Type & Bits/s \\
\hline P4 & $\begin{array}{c}\text { Cold Moments (H, } \\
\text { He++) }\end{array}$ & 83 \\
\hline P8 & 3D Cold 31E 8@ 8థ & 3984 \\
\hline P10 & 2D Hot 31E 16Ф & 1002 \\
\hline P14 & 2D Cold 31E $8 \Phi$ & 500 \\
\hline P18 & 1D Hot 31E & 63 \\
\hline
\end{tabular}

- 3-D distribution functions with flexible resolution in angle and energy;

- 2-D pitch-angle distributions using the onboard link with the magnetometer;

- 2-D azimuthal distributions.

Sampling time is 1 or $2 \mathrm{~ms}$ and the energy sweep period is $31.2,62.5$ or $125 \mathrm{~ms}$. 

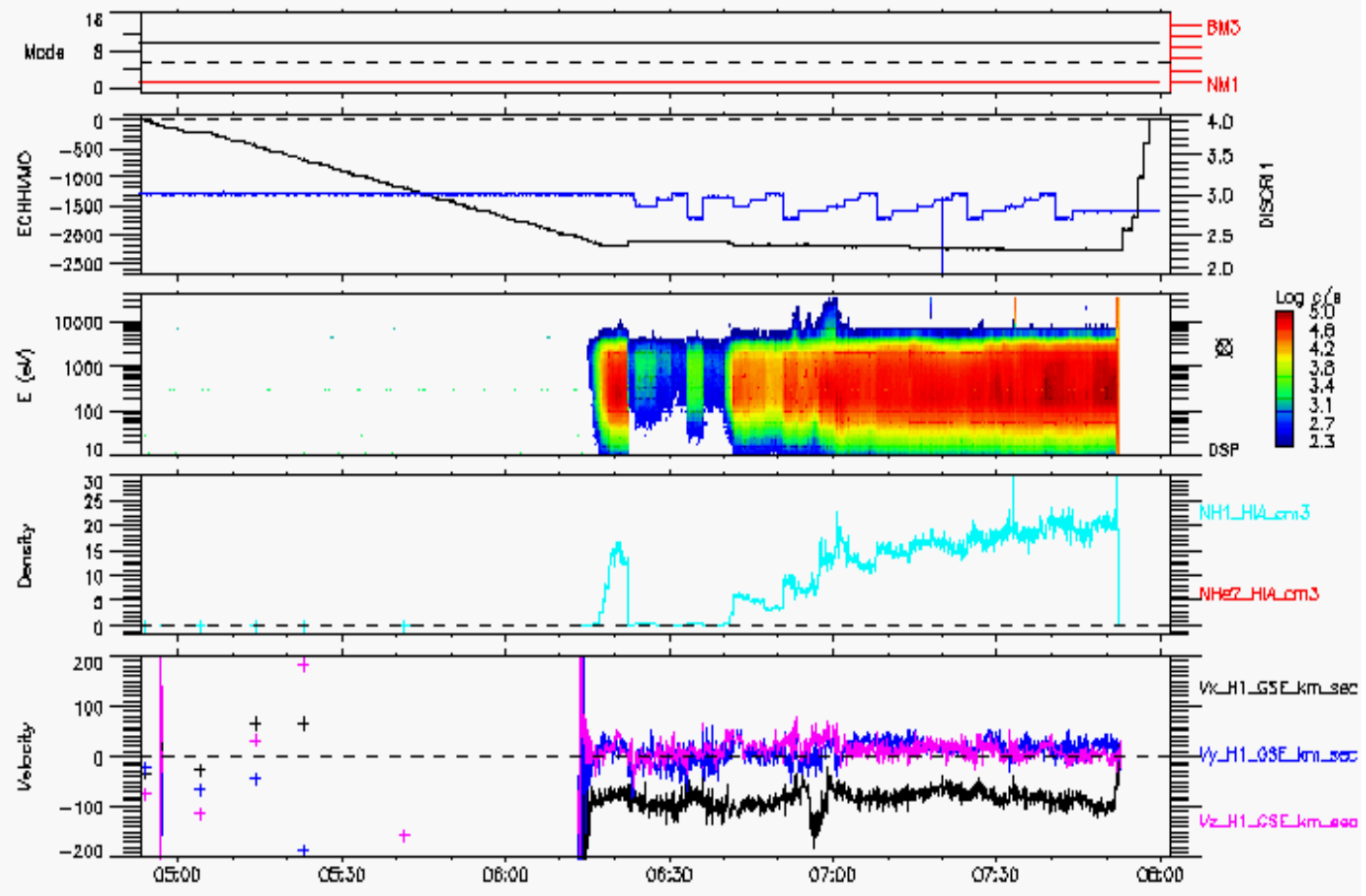

Fig. 4. HIA first data, on 9 February 2004. From top to bottom: upper panel shows the telemetry mode in red (there is no Burst Mode on TC-1) and the experiment mode in black; the next panel gives the MCP High Voltage in black and the discriminator threshold in blue; the next panel gives the HIA counting rate as a function of the energy; the next one shows the ion density (in solar wind mode proton density in blue/green and $\mathrm{He}^{++}$ions in red); at the bottom the 3 components of the ion speed in the GSE system are shown.

Table 4. HIA diagnostic products.

\begin{tabular}{|c|c|c|}
\hline Number & Type & Bits/s \\
\hline P0 & HV sweeping steps & 256 \\
\hline P1 & 32E 48 counters & 6144 \\
\hline
\end{tabular}

The DSDS (Double Star Science Data System) HIA parameters (see also Sect. 4.2) are moments of the ion distribution functions. These parameters include density, ion bulk velocity, parallel and perpendicular temperatures.

To calculate moments on board, integrals over the distribution function are approximated by summing products of measured count rates with appropriate energy/angle weighting over the sampled distribution. The moments are then log-compressed to 12 bits. Calibration factor corrections, conversion to physical units, and coordinate transformations are performed on the ground. The parallel and perpendicular temperatures are calculated on the ground from the onboard calculated pressure tensor, either by using the magnetic field direction derived from FGM PSDS data, or by diagonalising the pressure tensor (but with a degraded precision, depend-
Table 5. HIA nominal operation magnetospheric modes.

\begin{tabular}{|c|c|c|}
\hline Mode & Type & Products \\
\hline 7 & PROM & P0 / P1 \\
\hline 8 & Magnetosphere 1 & P2 / P6 / P12 \\
\hline 9 & Magnetosphere 2 & P2 / P6 / P19 \\
\hline 10 & Magnetosphere 3 & P2 / P9 / P17 \\
\hline
\end{tabular}

ing on the anisotropy of the distribution function). The FGM PSDS data are averaged magnetic field values.

HIA moments are calculated from the analyser "high G" half during magnetospheric modes (the only modes systematically used on the TC-1 spacecraft), and from the "low g" half during solar wind modes. During magnetospheric modes, count rate summing is performed over $360^{\circ}$ in azimuth (one full spin). During solar wind modes, summing is 


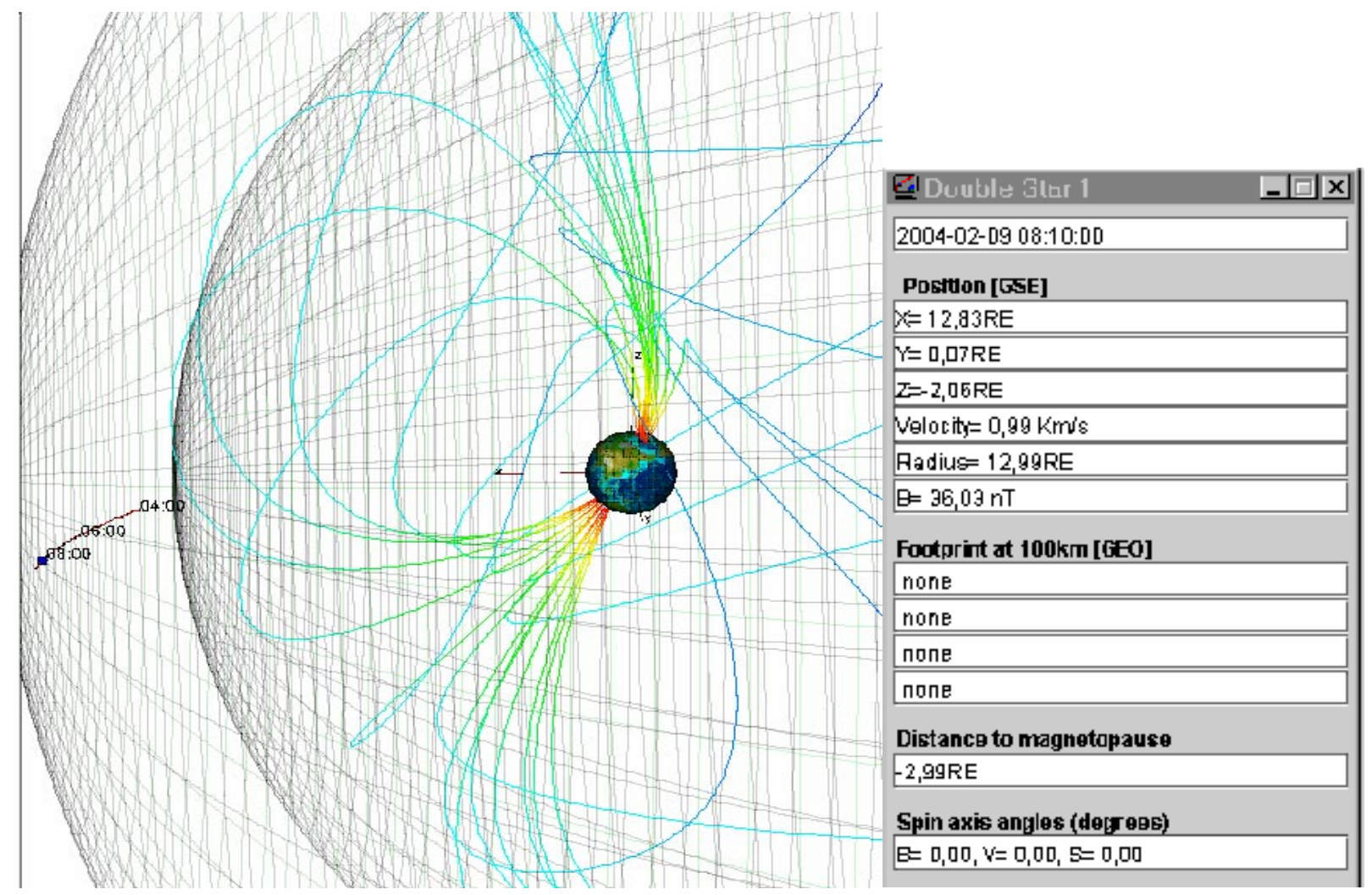

Fig. 5. TC-1 position during the 9 February 2004 tests using the Orbit Visualisation Tool developed by the OVT team for Cluster and DSP. The nominal position of the magnetopause and of the bow shock are clearly seen.

Table 6. HIA nominal operation solar wind modes

\begin{tabular}{|c|c|c|}
\hline Mode & Type & Products \\
\hline 0 & Solar Wind 1 & P4 / P8 / P10 \\
\hline 1 & Solar Wind 2 & $\begin{array}{c}\text { P4 / P10/P14 } \\
/ \text { P18 }\end{array}$ \\
\hline
\end{tabular}

performed over a sector of $45^{\circ}$ in azimuth and $45^{\circ}$ in elevation, centred on the main solar wind direction.

\section{HIA Data in different regions of the magnetosphere and in the solar wind}

HIA commissioning took place in CSSAR, Beijing, from 413 February 2004. All operations went very well. Nominal Operations started on 23 February 2004 at 19:20 UT.

Main points:

- Housekeeping data are nominal from the beginning;

- Commands are all received and executed;
- Science data are of very good quality (except when the telemetry reception becomes noisy) and yielded new information in the regions studied;

- Instrument reset is performed at the beginning of each planning period (once per week), for those that do not include an instrument switch off.

\subsection{First HIA commissioning data: magnetosheath}

The first data obtained by HIA, on 9 February 2004, between 06:15 and 07:50 UT, are shown in Fig. 4. TC-1 was inside the magnetosheath (see Fig. 5) and MCP High-Voltage and Discriminator Level settings were tested during this event. From the top the instrument mode, the MCP high voltage and the discriminator levels, the ion energy spectra, the density and the velocity components are shown. Variations in the energy spectra and in the density are mainly connected to changes in the MCP high voltage and the discriminator levels. Between 07:40 and 07:50 UT values are nominal.

\subsection{First HIA commissioning data: dayside plasma sheet}

Figure 6 shows the data obtained by HIA, on 10 February 2004, between 02:35 and 04:20 UT. TC-1 was inside the 


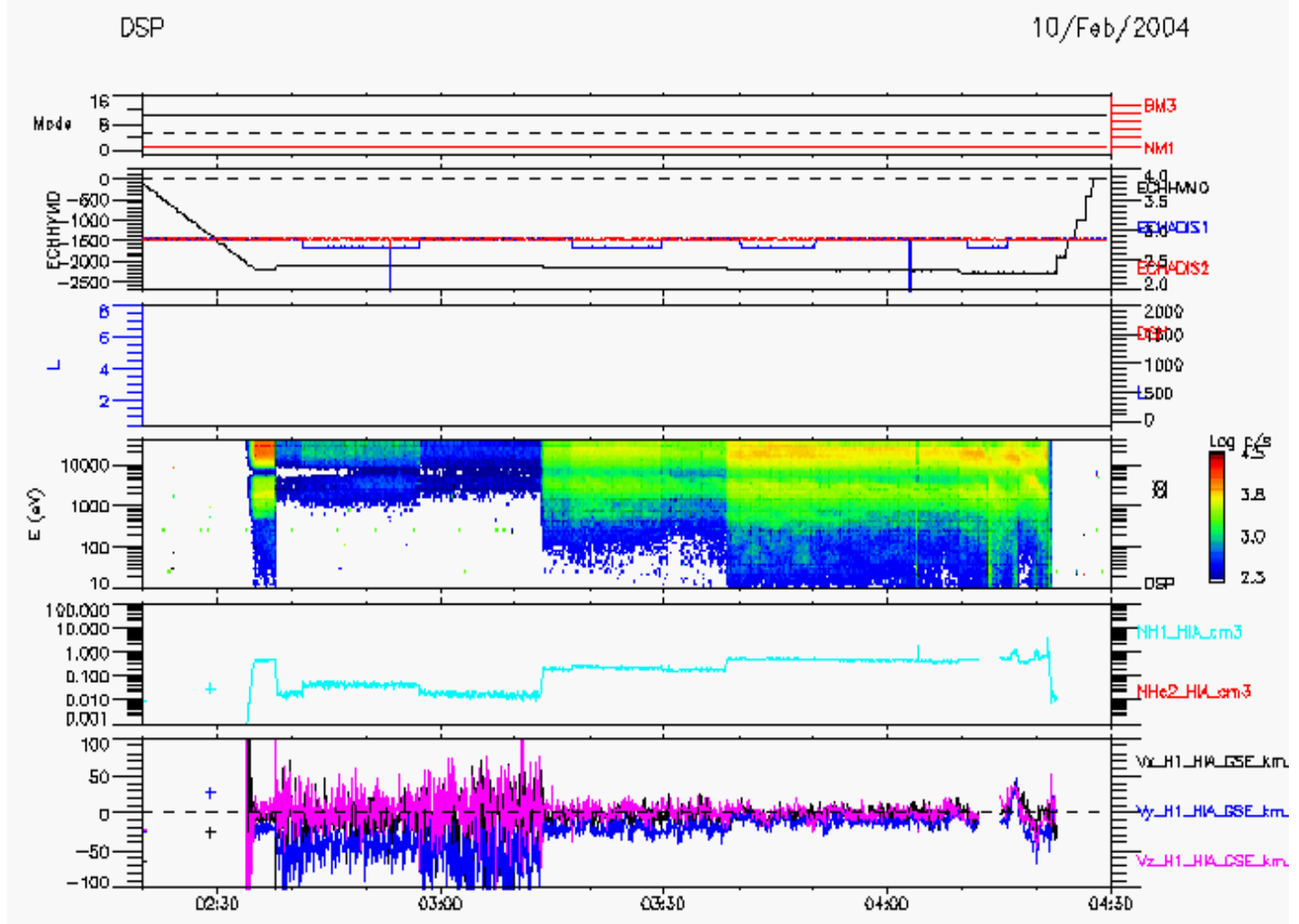

Fig. 6. HIA data on 9 February 2004.

Dayside Plasma Sheet (see Fig. 7) and MCP High-Voltage and Discriminator Level settings were also tested during this event. From the top the instrument mode, the MCP high voltage and the discriminator levels, the ion energy spectra, the density and the velocity components are shown. Variations in the energy spectra and in the density are mainly connected to changes in the MCP high voltage and the discriminator levels. Between 03:40 and 04:20 UT values are nominal.

3.3 First HIA commissioning data: ring current and radiation belts

Figure 7 shows the data obtained by HIA, on 12 February 2004, between 04:35 and 09:20 UT. TC-1 was inside the Ring Current and Radiation Belts, and MCP High-Voltage and Discriminator Level tests were completed for this event. From the top the instrument mode, the MCP high voltage and the discriminator levels, the ion energy spectra, the density and the velocity components are shown. Energy bands, outer belt injections, energy dispersion and ring current structure are detected.

After analysis of the commissioning data, the decision was made to operate the instrument normally in the outer radiation belt, and to operate the instrument with a reduced MCP high-voltage in the inner belt (for $\mathrm{L}<2.3$ ).

\subsection{First HIA commissioning data: solar wind}

The apogee of TC- 1 is about $2 \mathrm{R}_{E}$ higher than scheduled before the launch. As a result, TC-1 is found in the solar wind during a part of each year. This was the case at the beginning of the mission.

Figure 8 shows the data obtained by HIA, on 12 February 2004, between 12:00 and 22:00 UT. TC-1 was inside the magnetosheath and the solar wind. From the top the instrument mode, the ion energy spectra, the density and the velocity components are shown. Magnetosheath data are clearly identified with many ions between about $100 \mathrm{eV}$ and $10 \mathrm{keV}$. Solar wind ions are identified by the narrow and intense energy band around $2 \mathrm{keV}$. The interest of the TC- 1 orbit is linked to the fact that the trajectory of TC- 1 is very close to the bow shock (skimming orbit) and multiple traversals of the bow shock are clearly identified: between 15:30 and 22:00 UT more than 20 shock traversals are seen, TC- 1 goes back to the magnetosheath for a while. Upstream ions are also detected above the solar wind energies. The ion densities shown in Fig. 8 are underestimated, because during this period the instrument was being tested with reduced MCP high voltages.

\subsection{HIA data on Double Star: solar wind near the shock}

An interesting case of solar wind observation near the bow shock is the one of 24 February 2004, as seen in Fig. 5, 
DSP HIA $12 / \mathrm{Feb} / 2004$

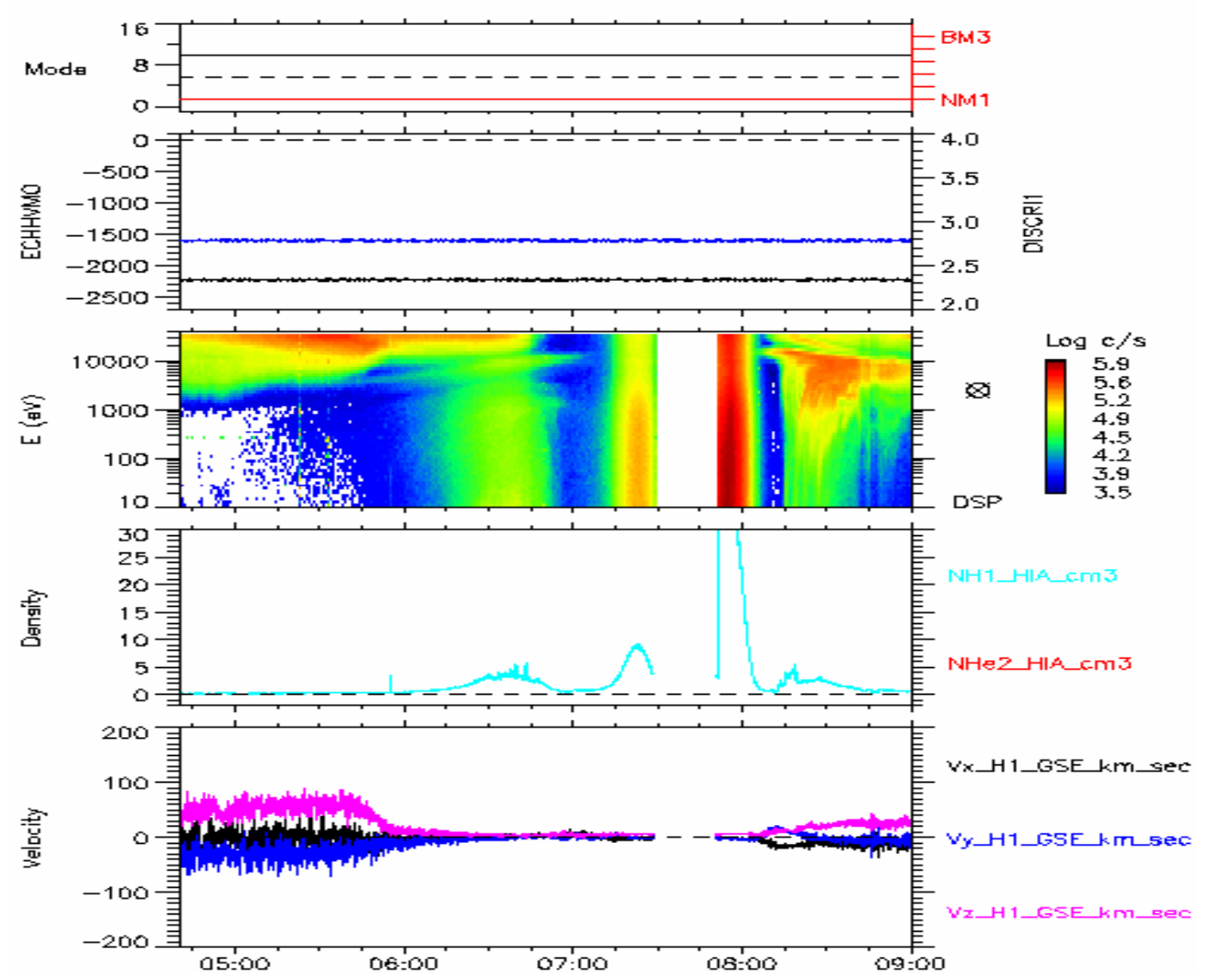

Fig. 7. HIA data on 12 February 2004 near perigee.

which shows the data obtained by HIA on 24 February 2004, between 08:00 and 11:00 UT. From the top the instrument mode, the ion energy spectra, the density, the velocity components and the temperature components are shown. TC-1 was first inside the magnetosheath, then in the solar wind near 08:40, returning back to the magnetosheath between 09:30 and 09:40 UT, returning back to the solar wind until about 10:10 UT and then coming back to the magnetosheath. Still, magnetosheath data are clearly identified by the ions between about $100 \mathrm{eV}$ and $10 \mathrm{keV}$. Solar wind ions are identified by the narrow energy band around $2 \mathrm{keV}$. Upstream ions are also detected above the solar wind energies, mainly between 08:40 and 09:12 UT . In the solar wind there is also a second narrow band above the main one: this second band (much less intense) is due to the solar wind $\mathrm{He}^{++}$ions, whereas the main band is due to the $\mathrm{H}^{+}$ions. So, $\mathrm{H}^{+}$and $\mathrm{He}^{++}$ions are identified by these two energy bands, showing that HIA is able to achieve comprehensive solar wind measurements even when HIA is operated in a magnetospheric mode, as it is on TC-1.

The data are collected here under the conditions of the quasi perpendicular shock (Möbius et al., 2001; Mazelle et al., 2003). Upstream particles (e.g. between 08:40 and
09:10 UT with energies greater than solar wind particles) are seen in all directions, with beamlets which are not homogeneous.

Figure 10 focuses on a small portion of this event between 09:20 and 09:50 UT. The motion of the spacecraft through the shock is very slow, due to the skimming orbit, and it is possible to measure the solar wind deceleration and the transition region between the solar wind and the magnetosheath with the mixture of the two populations. The solar wind is identified by the 2 parallel bands: the red band corresponds to the $\mathrm{H}^{+}$ions and the yellow one to the $\mathrm{He}^{++}$ions. Around 09:30 UT TC-1 is going inside the magnetosheath for a while with a clear deceleration of the solar wind ions. TC-1 is coming back to solar wind around 09:40 UT, also with energy dispersion.

\subsection{HIA data on Double Star: inside the bow shock}

On 25 February 2004 a very nice event of spacecraft relative motion inside the bow shock was detected. TC-1 is at the outbound leg of its orbit, very close to the apogee (very small spacecraft radial velocity). Due to its unique orbit, with an 


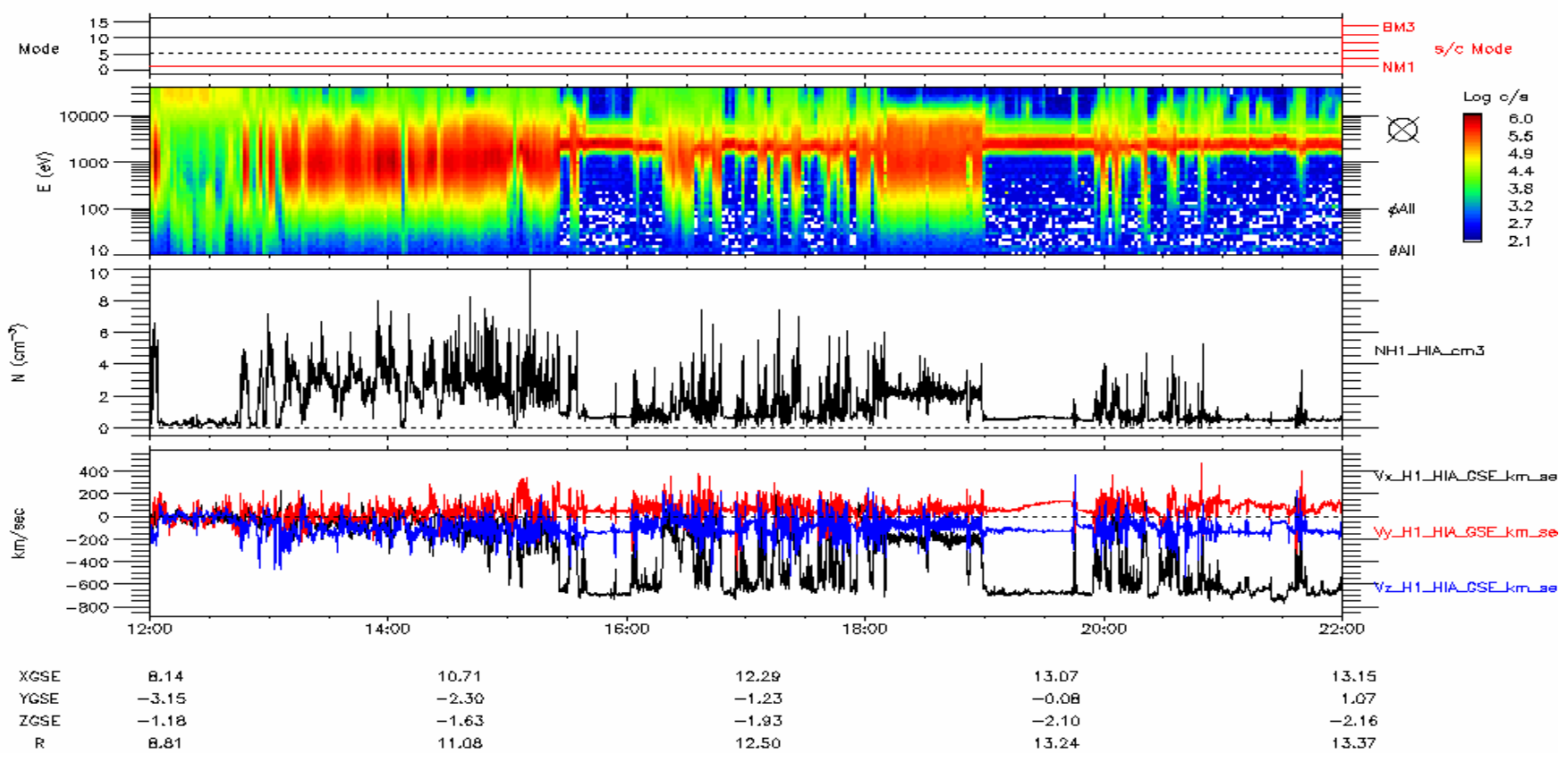

Fig. 8. HIA data on 12 February 2004 near and in the interplanetary medium.

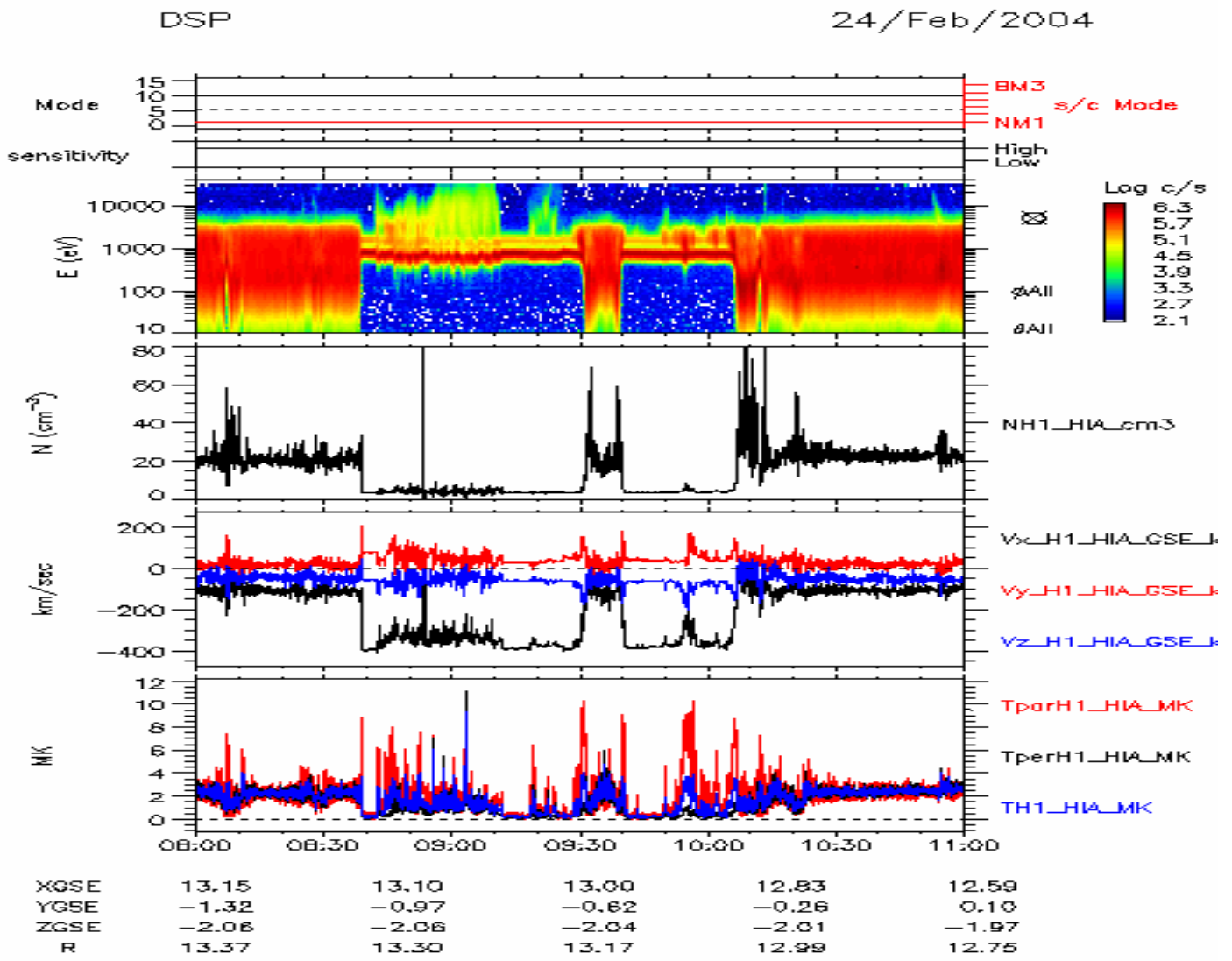

Fig. 9. HIA data on 24 February 2004 near and in the interplanetary medium. 


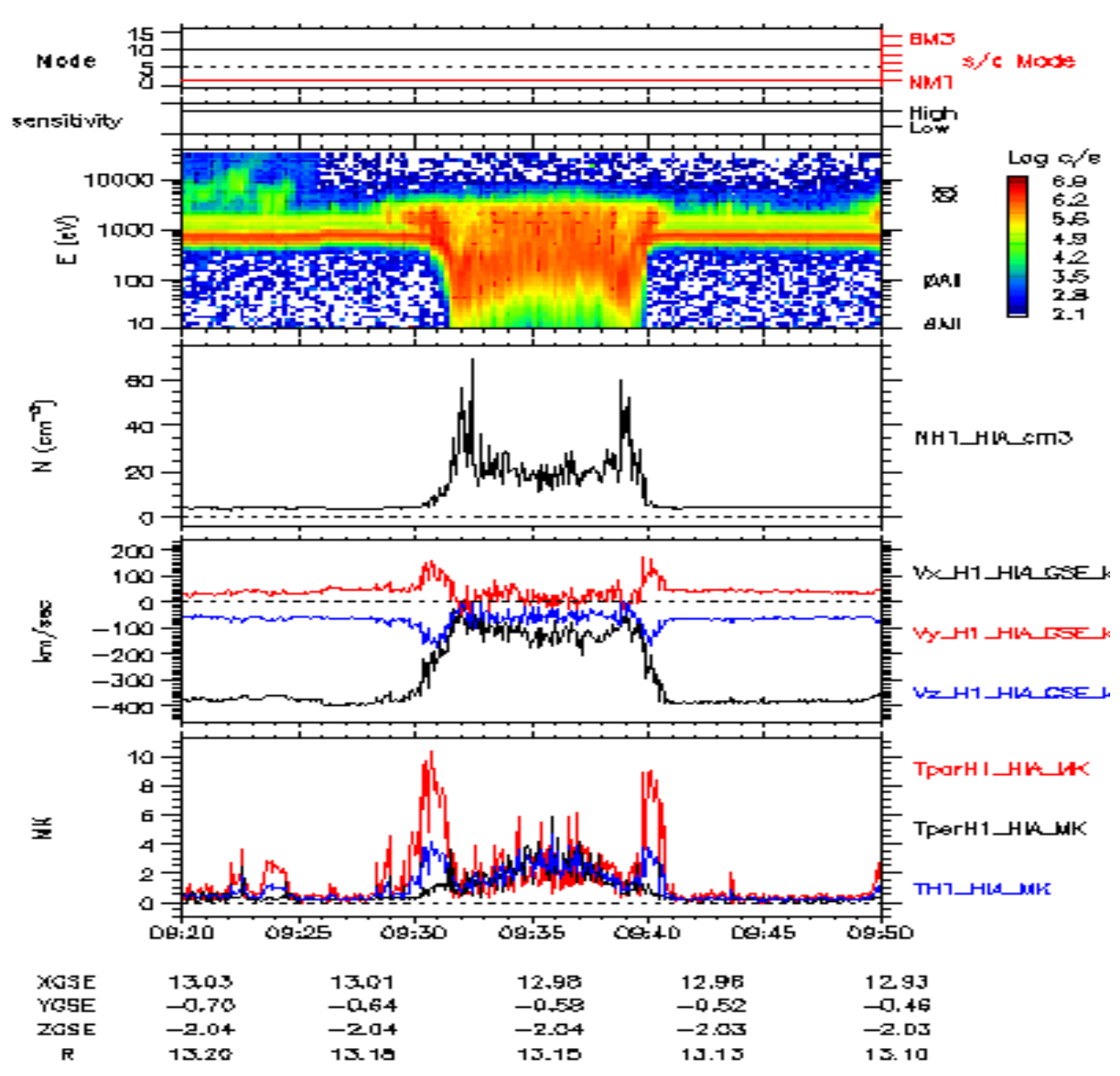

Fig. 10. HIA data on 24 February 2004: example of a transit in the magnetosheath with energy dispersion.

apogee around 13.5 Earth radii of geocentric distance, TC1 skims along the bow shock. Therefore, TC-1 has a better chance to observe the bow shock for relatively longer intervals than other spacecraft that have visited this region. Figure 11 shows the data obtained by HIA, between 06:50 and 07:30 UT. From the top the instrument mode, the ion energy spectra, the density, the velocity components and the temperature components are shown. Magnetosheath and solar wind data are clearly seen with the separation in two energy bands in the solar wind $\left(\mathrm{H}^{+}\right.$and $\mathrm{He}^{++}$ions) still visible. Until about 07:04 UT TC-1 is in the magnetosheath, as can be seen from the broad ion energy spectrum, with the density greater than $20 \mathrm{~cm}^{-3}$, and the $\mathrm{V}_{x}$ velocity component around $-100 \mathrm{~km} / \mathrm{s}$. Between 07:04 and 07:13 UT, TC-1 is almost stationary inside the bow shock. This allows the HIA instrument to measure the shocked solar wind, with the thermalisation process that transforms the solar wind kinetic energy into thermal energy and the acceleration of the ion population.
Upstream particles, with an energy above about $2 \mathrm{keV}$, generated inside the bow shock, are seen above the broad energy band of the magnetosheath ions. Some of these ions have energies which are too high to be detected by HIA, showing that the acceleration mechanism is strong. These upstream ions are detected with a clear energy dispersion (Louarn et al., 2003). Strong bursts of low frequency waves (not shown) are simultaneously detected by the STAFF instrument inside the shock and might play a role in this process. Before the entrance in the solar wind the thermalization of the wind is very clear near 07:13 UT and also near 07:16 UT when the spacecraft leaves the solar wind. This is a very rare observation of the physical processes taking place within the bow shock, which is flapping over the spacecraft and the spacecraft stays within it for such a long interval that it allows one to measure in detail the complete ion distribution functions. Note, too, that the Cluster spacecraft go through the bow shock much more quickly. 


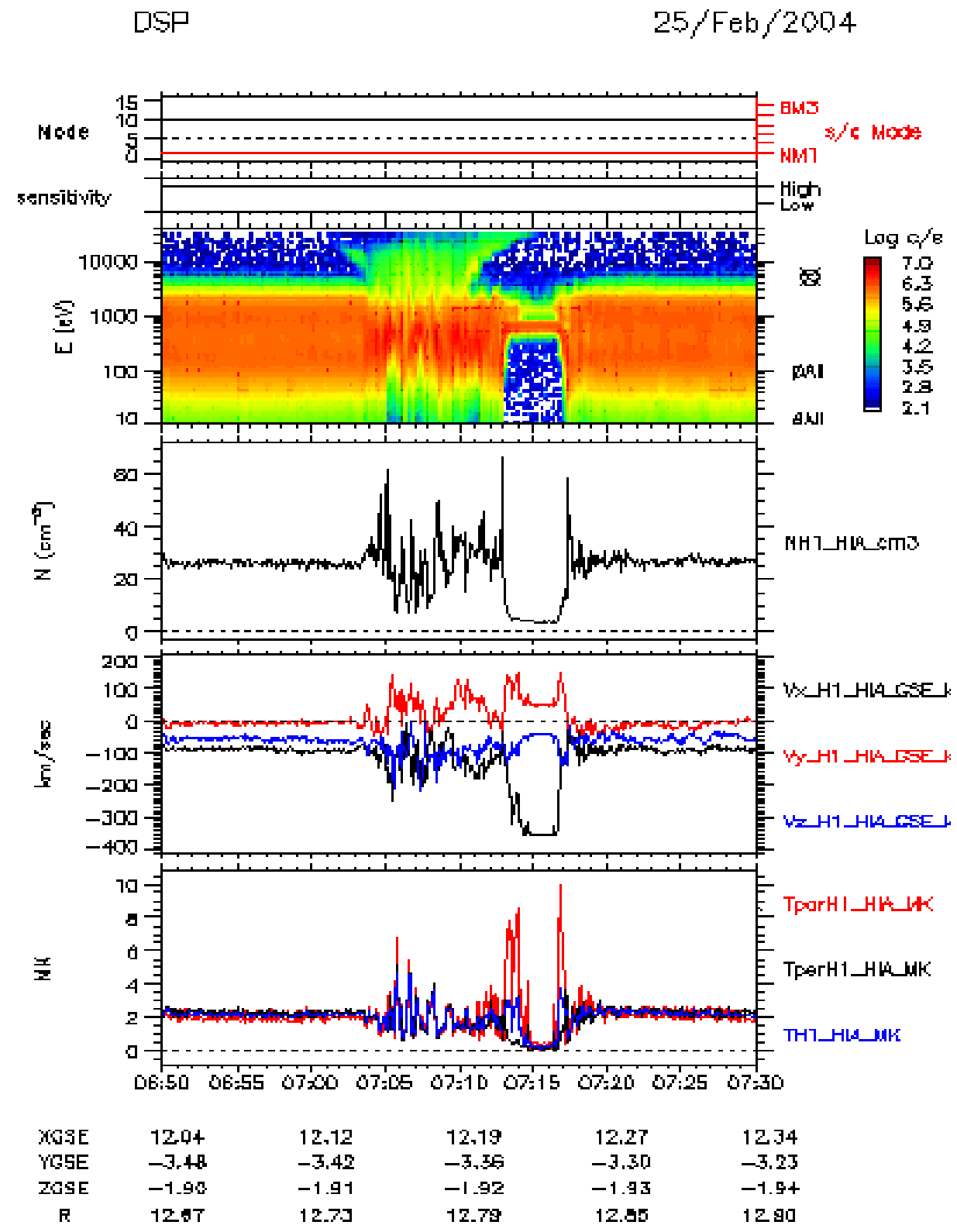

Fig. 11. HIA data on 25 February 2004: example of a long transit in the bow shock.

3.7 HIA data on Double Star: transition between the magnetosheath and the plasma sheet

On 24 February 2004 a good example of the magnetosheathdayside plasma sheet transition, with a boundary layer was detected. Figure 12 shows the data obtained by HIA, on 24 February 2004, between 14:00 and 16:00 UT. From the top the instrument mode, the ion energy spectra, the density, the velocity components and the temperature components are shown.

Magnetosheath ions are characterized by very strong fluxes in the $20-3000 \mathrm{eV}$ energy band. Plasma sheet ions have higher energies but much lower fluxes, as it can be seen from about 15:14 UT. Just before, between 14:45 and 15:14 UT, thanks to its orbit TC-1 is in a boundary layer with a mixture of the two ion populations.

\subsection{HIA data on Double Star: morning plasma sheet}

On 1 April 2004 TC-1 is in the morning-side plasma sheet. Figure 13 shows the data obtained by HIA, between 13:00 and 16:00 UT. From the top the instrument mode, the ion energy spectra, the density, the velocity components and the temperature components are shown. In this example TC-1 is going outbound in the morning-side plasma sheet. 
DSP 24/Feb/2004

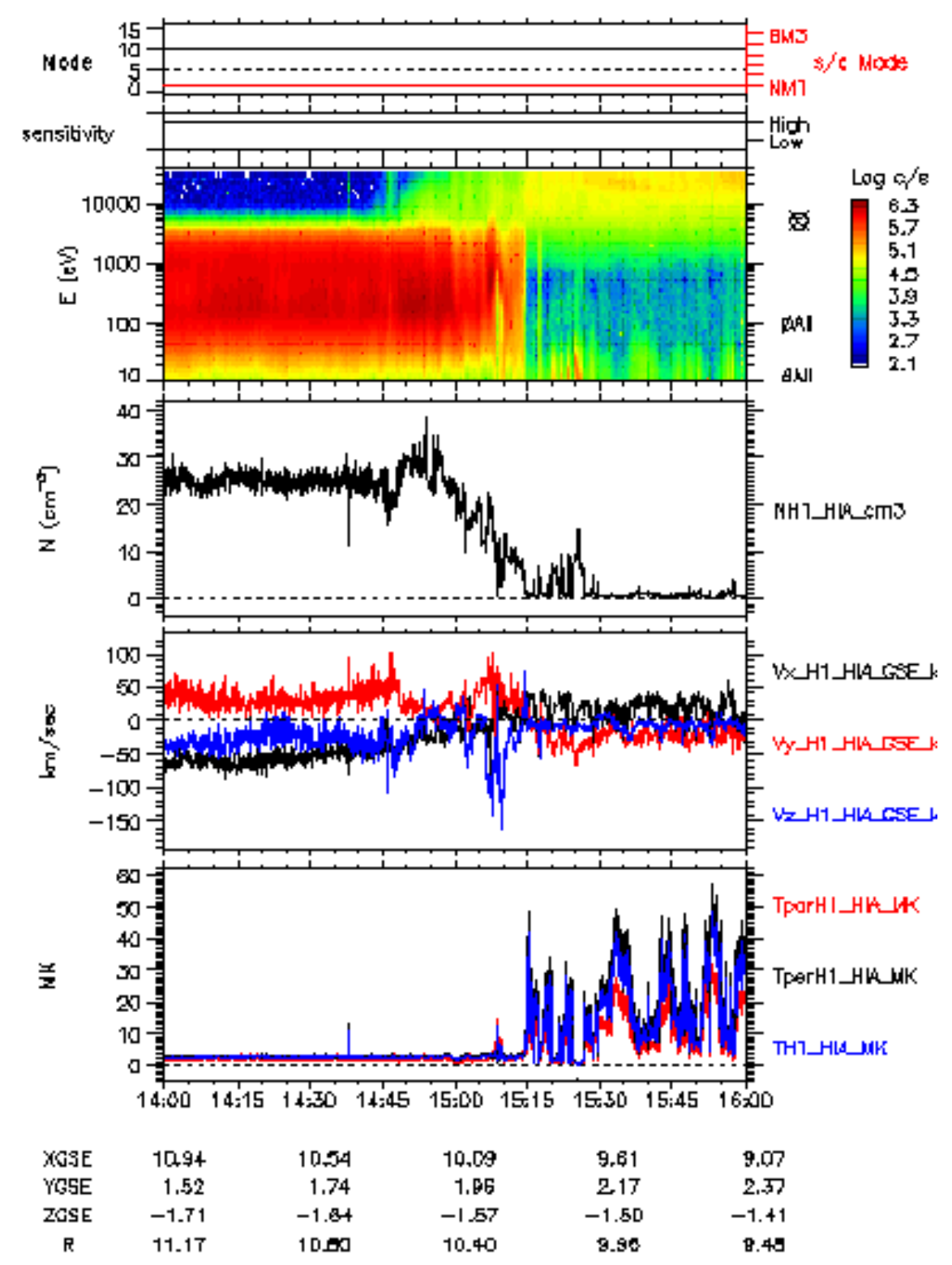

Fig. 12. HIA data on 24 February 2004: example of a transition between the magnetosheath and the plasma sheet.

In Fig. 14 an example of Ion Distribution Functions on 1 April 2004 at 14:08:10 UT is shown. The 3 upper panels give in the GSE system, from left to right: $V_{y}$ in function of $\mathrm{V}_{x}, \mathrm{~V}_{z}$ in function of $\mathrm{V}_{x}$ and $\mathrm{V}_{z}$ in function of $\mathrm{V}_{y}$. Counterstreaming beams are detected, as seen in the opposite direction fluxes in red for the 2 distributions in function of $\mathrm{V}_{z}$ in Fig. 14. In Fig. 13 velocity modulations, especially on the $\mathrm{V}_{x}$ component, are detected and the beamlets are dispersed in energy as seen by Keiling et al. (2004) with Cluster.
3.9 HIA data on Double Star: example of outer radiation belt, ring current and nightside plasma sheet traversal

On 28 May 2004, between 12:00 and 16:00 UT, TC-1 is going through the outer radiation belt, the ring current and the nightside plasma sheet. Figure 15 shows the data obtained by HIA in this time interval. From the top the instrument mode, the ion energy spectra, the density, the velocity components and the temperature components are shown. Initially, TC-1 was in the space between the inner and the outer radiation belts, and then it entered into the outer radiation belt from about 12:14 to 12:42 UT. The transition from the 


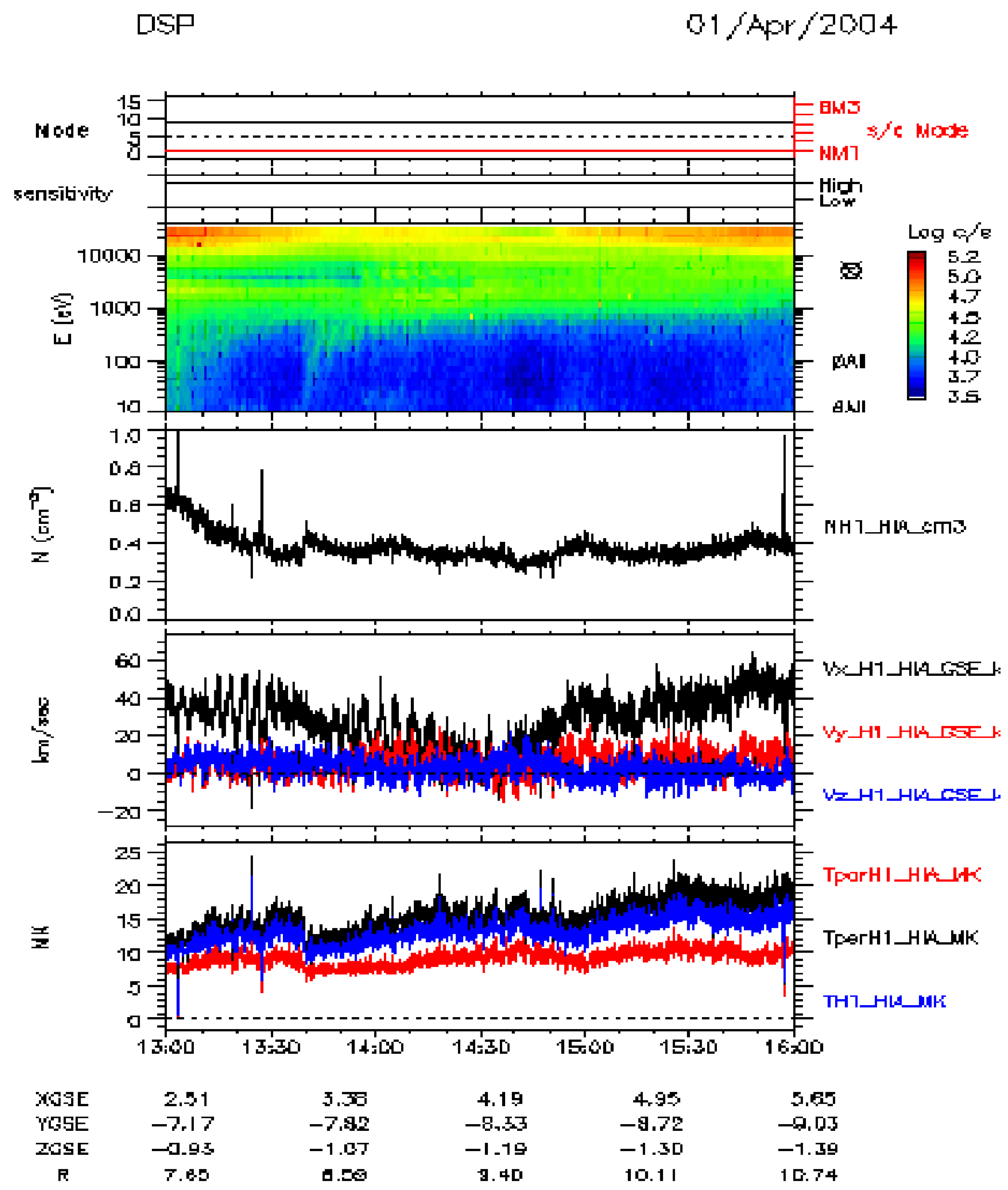

Fig. 13. HIA data on 1 April 2004: example of morning plasma sheet and outbound traversal.

ring current to the nightside plasma sheet is then observed at about 13:20 UT (Vallat et al., 2004). Injections are clearly seen between about 13:00 and 15:00 UT and the plasma sheet is not stable.

3.10 HIA data on Double Star: example of plasma sheet thinning

On 14 September 2004, between 08:30 and 12:00 UT, TC1 is in the nightside plasma sheet. Figure 16 shows the data obtained by HIA in this time interval. From the top the instrument mode, the ion energy spectra, the density, the velocity components and the temperature components are shown. In this example, a plasma sheet thinning (Dandouras et al., 1986) is shown just before 10:00 UT, associated with magnetic field dipolarisation. At plasma sheet recovery, a fast tailward flow is seen, then an earthward plasma flow is observed in the expanding plasma sheet (Nakamura et al., 2002).

\section{HIA data processing and operations}

\subsection{HIA data processing architecture}

The overall software architecture is the same as for Cluster, with 3 main levels: 


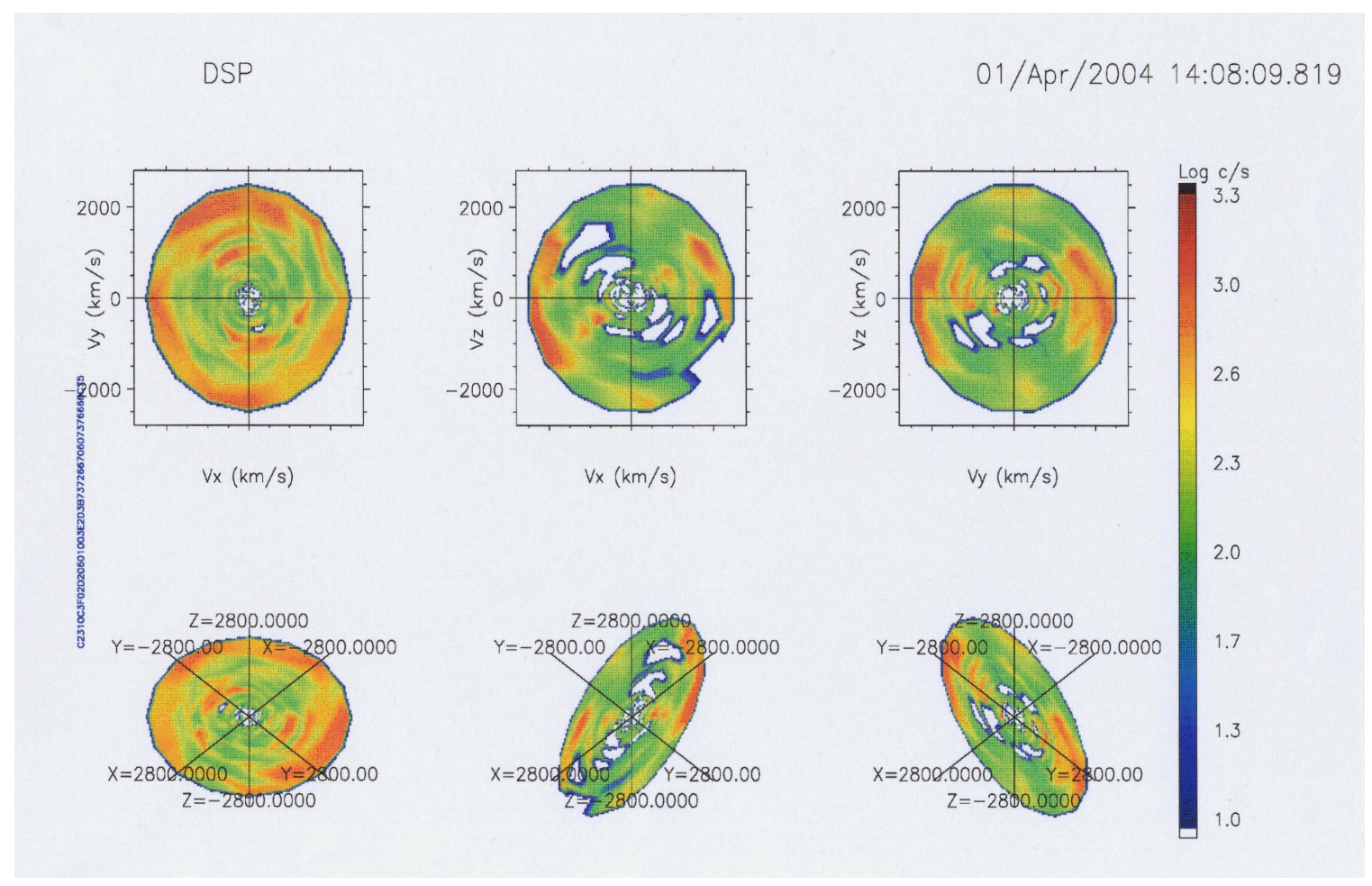

Fig. 14. Example of distribution function of the ions on 1 April 2004 at 14:08:10 UT.

- HIA Level 1-D (equivalent to CIS L1 for Cluster): TM decommutation and decompression, time tagging, organisation in raw product files;

- HIA Level 2 (equivalent to CIS L3 for Cluster): High Resolution Science Products (calibration-corrected);

- HIA Level 3 (equivalent to CIS L2 for Cluster): DSDS (Double Star Science Data System) Data Products (PPD and SPD, see below);

- Near real-time data on the Web are on the DSDSWeb (equivalent to the CSDSWeb for Cluster).

\subsection{HIA data in the DSDS}

The HIA raw telemetry data are systematically processed at CESR, and the resulting Level 3 Data Products are delivered to CNES and ingested into the database. These are then made available through the DSDS (Torkar et al., 2004). Level 3 files are CDF files in physical units, and they include density, bulk velocity, parallel and perpendicular temperatures. These files are organised following the Double Star Science Data System (DSDS) recommendations, and they populate two databases: the Prime Parameter Database (PPDB: 4-s resolution) and the Summary Parameter Database (SPDB: 1-min resolution). The contents of these databases are distributed to the National Data Centres on a daily basis. The PPDB are accessible to the whole Double Star community, and the SPDB are public domain. Due to their broad accessibility, and to the quality of their data products, these databases must permit joint analysis of plasma parameters from several instruments, further enhancing the science return of the Double Star and Cluster missions.

In addition to the ion moments (density, ion bulk velocity in the GSE system, parallel and perpendicular temperatures), a "status word" is added to the HIA DSDS products. This status word is a string of four 1-byte unsigned integers:

Status [0] Data quality as defined by DSDS.

Status [1] Shows the HIA telemetry data product used to generate the DSDS parameters "Key Products" (cf. Table 7).

Status [2] Gives the CIS Operational Mode (0-15, cf. Table 1).

Status [3] Spare.

- Caveats

The user of the HIA DSDS parameters needs to be cautious. These parameters are only moments of the distribution functions, which result from summing counting rates. Thus, they do not convey information on the detailed structure of the 3-D distributions.

Counting statistics are essential for obtaining reliable results. Besides instrument sensitivity and calibration, the accuracy of computed moments is mainly affected by the finite energy and angle resolution, and by the finite energy range of the instruments. 
DSP

$28 / \operatorname{May} / 2004$

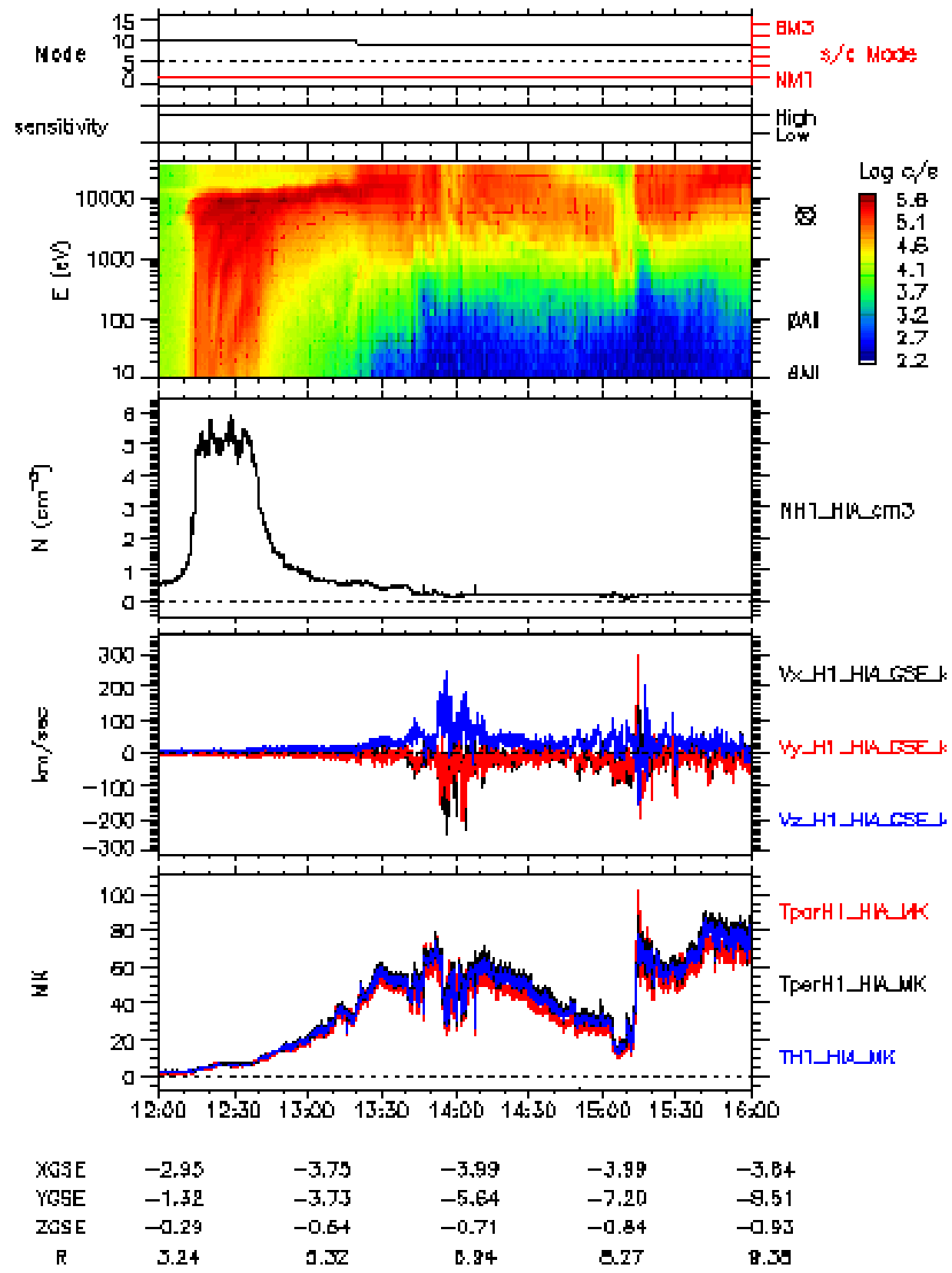

Fig. 15. HIA data on 28 May 2004: example of outer radiation belt, ring current and nightside plasma sheet traversal.

Table 7. Value of the product used to generate the DSDS parameters.

\begin{tabular}{lll}
\hline Value & $\begin{array}{l}\text { HIA T/M } \\
\text { Product }\end{array}$ & Comments \\
\hline 2 & P2 & Used during magnetospheric modes: Distribution function summed over $360^{\circ} \times 180^{\circ}($ azimuth $\times$ elevation $)$ \\
4 & P4 & Used during solar wind modes: Distribution function summed over $45^{\circ} \times 45^{\circ}($ azimuth $\times$ elevation $)$ \\
\hline
\end{tabular}




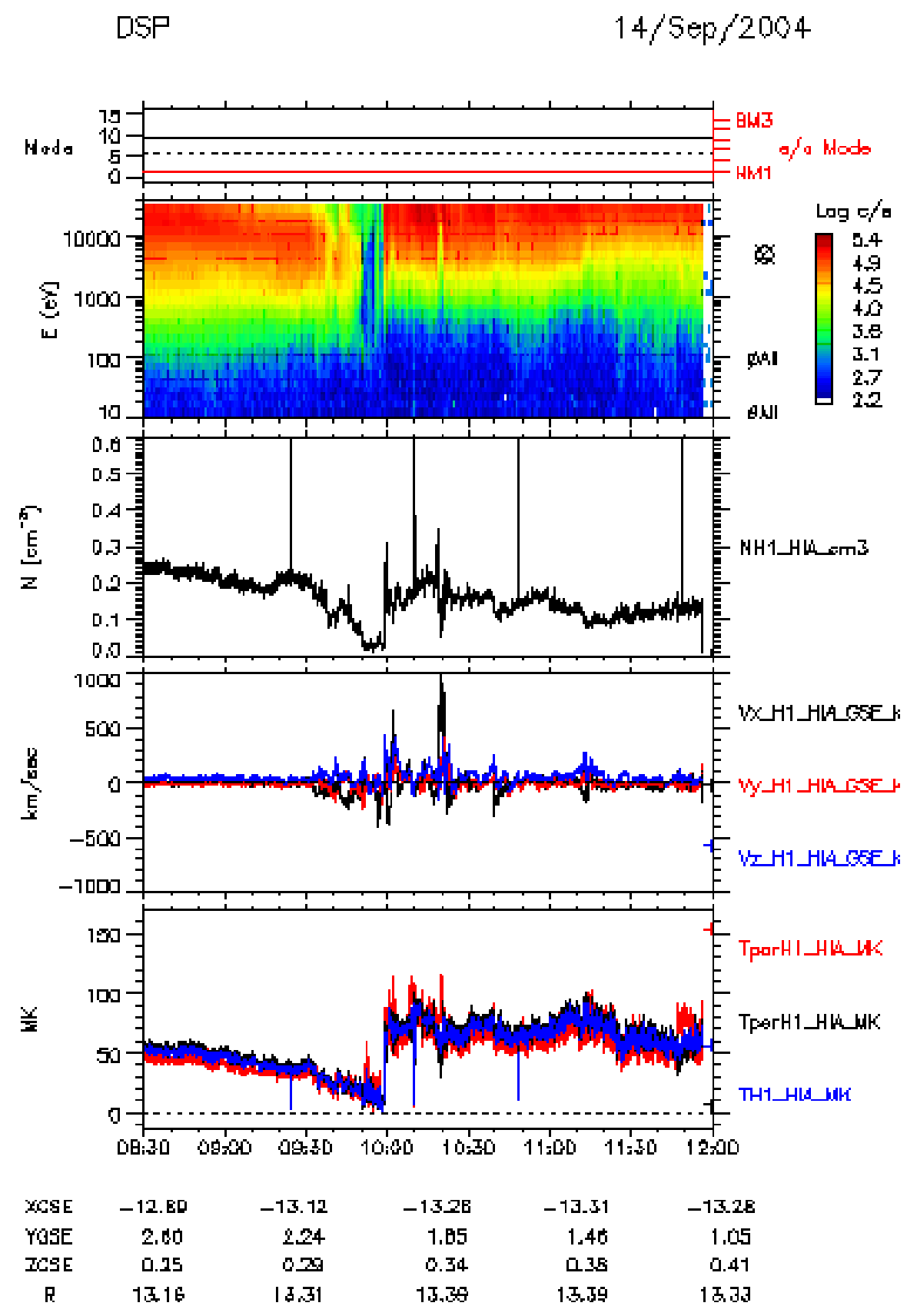

Fig. 16. HIA data on 14 September 2004: example of plasma sheet thinning.

At perigee, the HIA data can suffer from background due to penetrating particles from the radiation belts.

Spacecraft charging to a positive floating potential repels low-energy ions, which in these cases cannot be detected by HIA. The operation of the ASPOC ion emitter provides a helpful contribution in the detection of low-energy ions by HIA (particularly in low-density regions), by reducing the spacecraft potential. Spacecraft potential effects have thus to be taken into account for low-energy ions.
The HIA calibration values are regularly updated to take into account the detector efficiency evolution. However, as the evaluation of the detector efficiency requires some "time history", a necessity for a statistical analysis, there is a lag between the detector efficiency drift and the calibration updates. 


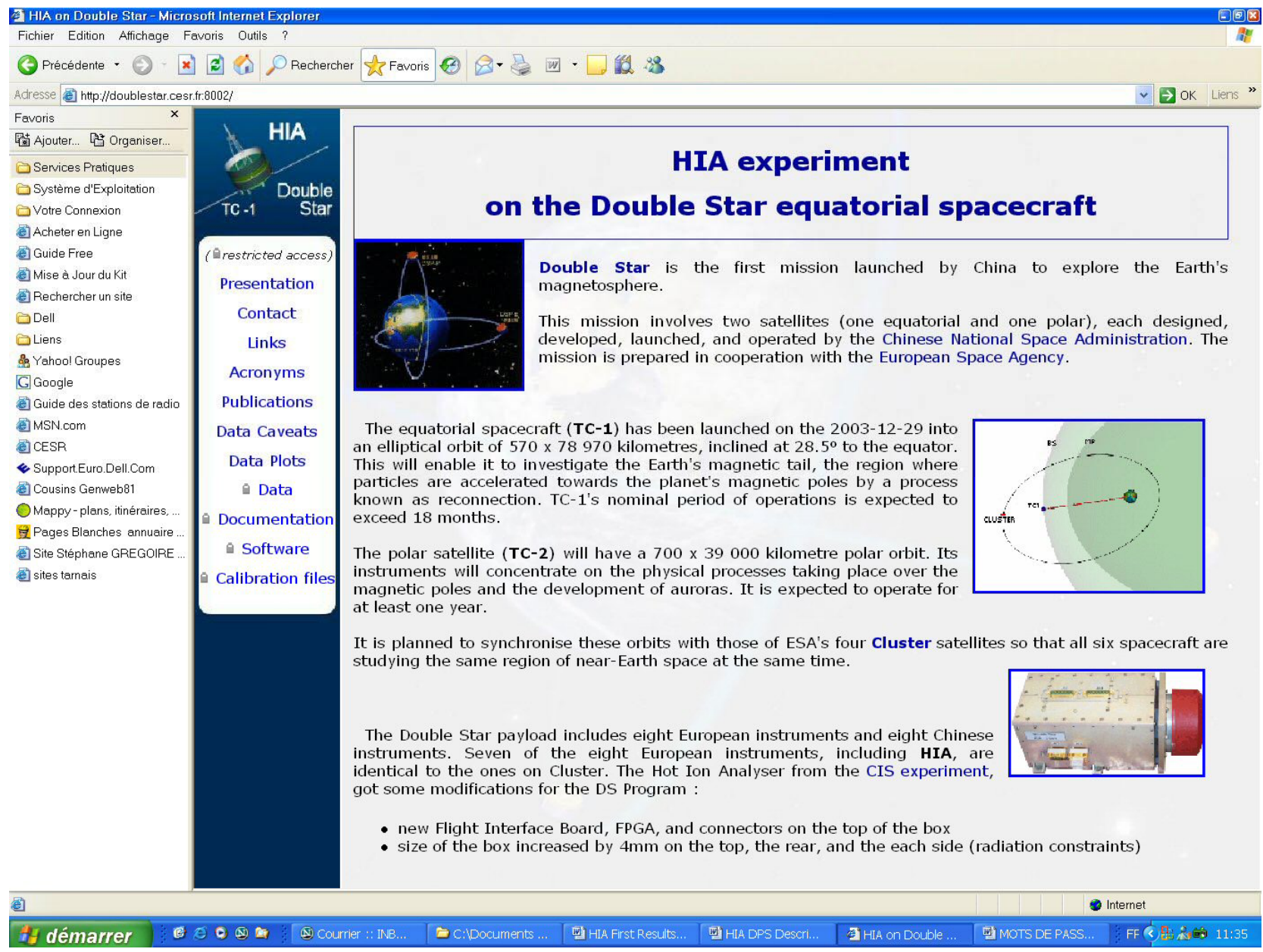

Fig. 17. Access page to the HIA Web server.

Preliminary information is given in the caveats server, maintained by the HIA team. Please consult the HIA home page given for the latest caveat information: http: //doublestar.cesr.fr:8002. The HIA Web server contains both public-access pages and HIA Co-I reserved pages (see Fig. 17). To understand the data it is necessary to read the caveats associated with these HIA pages and recall that Prime Parameters are not for publication and can only be used for identifying and selecting events.

\subsection{HIA high resolution data}

HIA high-resolution data (Level-1D), calibration files and processing software are available, for the HIA Co-Is, at the HIA Web server. The software ( $c l$ software, IDL based) is for processing and plotting HIA Level-1D and Level-2 data. It is interactive and provides a wide range of functionalities. This software can also read other (non-HIA) CDF or CEF files, for correlation studies, and can export the data in CEF (ASCII) format.

\section{Conclusions}

This paper first summarizes the instrument properties, the instrument telemetry modes, and the data processing of the HIA instrument on board the TC-1 spacecraft of the Double Star project. By showing then different examples of the results obtained by the HIA instrument on board TC-1 in the different regions of the magnetosphere and in the solar wind, we have demonstrated that the TC-1-Double Star orbit is unique for boundary studies. The coordinated measurements of TC- 1 and Cluster, with identical instruments, but very complementary orbits, will give many new results in the near future. 
Acknowledgements. The authors thank to all involved people at:

- CAST for the perfect HIA integration on the spacecraft,

- CSSAR for the perfect commanding of HIA during the commissioning,

- ASTRIUM for the big help during all the spacecraft operations during HIA integration,

- ESA for all the perfect job made to follow all the activities on Double Star,

- EPOS for the perfect commanding of the instrument, and the OVT team for the orbit visualisation tool.

HIA on Double Star was funded through CNES and ASTRIUM (ESA) grants.

Topical Editor T. Pulkkinen thanks P. W. Daly and S. J. Schwartz for their help in evaluating this paper.

\section{References}

Dandouras, J., Rème, H., Saint-Marc, A., Sauvaud, J. A., Parks, G. K., Anderson, K. A., and Lin, R. P.: A statistical study of plasma sheet dynamics using ISEE 1 and 2 energetic particle flux data, J. Geophys. Res., 91, 6861-6870, 1986.

Keiling, A., Rème, H., Dandouras, I., Bosqued, J.-M., Sergeev, V., Sauvaud, J.-A., Jacquey, C., Lavraud, B., Louarn, P., Moreau, T., Vallat, V., Escoubet, C. P., Parks, G. K., McCarthy, M., Moebius, E., Amata, E., Klecker, B., Korth, A., Lundin, R., Daly, P., and Zong, Q.-G.: New properties of energy-dispersed ions in the plasma sheet boundary layer observed by Cluster, J. Geophys. Res., 109, A05215, doi:10.1029/2003JA010277, 2004.

Louarn, P., Budnik, E., Sauvaud, J.-A., Parks, G. K., Meziane, K., Bosqued, J.-M., Dandouras, I., Rème, H., Mall, U., Daly, P., Dunlop, M., Balogh, A., Kistler, L. M., and Amata, E.: Observation of energy-time dispersed ion structures in the magnetosheath by CLUSTER: possible signatures of transient acceleration processes at shock, Ann. Geophys., 21, 1483-1495, 2003,

\section{SRef-ID: 1432-0576/ag/2003-21-1483.}

Mazelle, C., Meziane, K., LeQuéau, D., Wilber, M., Eastwood, J. P., Rème, H., Sauvaud, J.-A., Bosqued, J.-M., Dandouras, I., McCarthy, M., Kistler, L. M., Klecker, B., Korth, A., BavassanoCattaneo, M. B., Pallocchia, G., Lundin, R., and Balogh, A.: Production of gyrating ions from nonlinear wave-particle interaction upstream from the Earth's bow shock: a case study from Cluster-CIS, Planet. Space Sci., 51, 785-795, 2003.
Möbius, E., Kucharek, H., Mouikis, C., Georgescu, E., Kistler, L. M., Popecki, M. A., Scholer, M., Bosqued, J.-M., Rème, H., Carlson, C. W., Klecker, B., Korth, A., Parks, G. K., Sauvaud, J.-A., Balsiger, H., Bavassano-Cattaneo, M. B., Dandouras, I., DiLellis, A. M., Eliasson, L., Formisano, V., Horbury, T., Lennartsson, W., Lundin, R., McCarthy, M., McFadden, J. P., and Paschmann, G.: Observations of the spatial and temporal structure of field-aligned beam and gyrating ring distributions at the quasi-perpendicular bow shock with Cluster CIS, Ann. Geophys., 19, 1411-1420, 2001,

SRef-ID: 1432-0576/ag/2001-19-1411.

Nakamura, R., Baumjohann, W., Runov, A., Volwerk, M., Zhang, T. L., Klecker, B., Bogdanova, Y., Roux, A., Balogh, A., Rème, H., Sauvaud, J.-A., and Frey, H. U.: Fast flow during current sheet thinning, Geophys. Res. Lett., 29(23), 2140, doi:10.1029/2002GL016200, 2002.

Rème, H., Aoustin, C., Bosqued, J.-M., Dandouras, I., Lavraud, B., Sauvaud, J.-A., Barthe, A., Bouyssou, J., Camus, T., Cœur-Joly, O., Cros, A., Cuvilo, J., Ducay, F., Garbarowitz, Y., Medale, J.L., Penou, E., Perrier, H., Romefort, D., Rouzaud, J., Vallat, C., Alcaydé, D., Jacquey, C., Mazelle, C., d’Uston, C., Möbius, E., Kistler, L. M., Crocker, K., Granoff, M., Mouikis, C., Popecki, M., Vosbury, M. M., Klecker, B., Hovestadt, D., Kucharek, H., Kuenneth, E., Paschmann, G., Schöler, M., Sckopke, N. $\left(^{\dagger}\right)$, Seidenschwang, E., Carlson, C. W., Curtis, D. W., Lin, R. P., McFadden, J. P., Parks, G. K., Phan, T., Formisano, V., Amata, E., Bavassano-Cattaneo, M. B., Baldetti, B., Bruno, R., Chioncho, G., Di Lellis, G. M., Marucci, M. F., Korth, A., Daly, P. W.Graeve, B., Rosenbauer, H., Vasyliunas, V., McCarthy, M., Wilber, M., Eliasson, L., Lundin, R., Olsen, S., Shelley, E. G., Fuselier, S., Ghielmetti, A. G., Lennartsson, W., Escoubet, C. P., Balsiger, H., Friedel, R., Cao, J.-B., Kovrazhkin, R. A., Papamastorakis, I., Pellat, R., Scudder, J., and Sonnerup, B.: First multispacecraft ion measurements in and near the Earth's magnetosphere with the identical Cluster Ion Spectrometry (CIS) experiment, Ann. Geophys., 19, 1303-1354, 2001,

SRef-ID: 1432-0576/ag/2001-19-1303.

Torkar, K.: Users Guide to the Double Star science Data System, DSP-IWF-TN-0002, 2004.

Vallat, C., Dandouras, I., C:son Brandt, P., Mitchell, D. G., Roelof, E. C., deMajistre, R., Rème, H., Sauvaud, J.-A., Kistler, L., Mouikis, C., Dunlop, M., and Balogh, A.: First comparisons of local ion measurements in the inner magnetosphere with ENA magnetospheric image inversions: Cluster-CIS and IMAGE-HENA observations, J. Geophys. Res., 109, A04213, doi:10.1029/2003JA010224, 2004. 